\title{
PEHITUNGAN HARGA POKOK PRODUKSI PADA PT LENTERA ABADI SURAKARTA
}

\author{
Arifa Nur Azizah, Sulistiyo \\ Jurusan Akuntansi, Politeknik Negeri Semarang \\ Jl. Prof. H. Sudarto, S.H., Tembalang, Semarang 50275
}

\begin{abstract}
This Final Project aims to calculate the cost of production by the cost of order method on the end table product order and carved table and compare the results of PT Lentera Abadi Surakarta with the results of the study. The data used are primary data and secondary data including data about production cost determination conducted by PT Lentera Abadi Surakarta, and also company overview. Data collection methods use in this Final Project is interview, observation and documentation. Based on calculations and analysis that have been done, there is a difference in cost of production of the company by the job order costing method on the order end table amounting to Rp 27.512 and carved table orders of $R p$ 85.988. This difference occurs because in calculating the cost of production the company incorporates marketing costs, administrative and general costs into the components of factory overhead costs and not include PBB cost.
\end{abstract}

Keywords: Cost of Production, Job Order Costing Method

Abstrak: Penelitian ini bertujuan untuk melakukan perhitungan harga pokok produksi
dengan metode harga pokok pesanan pada pesanan produk end table dan carved table dan
membandingkan hasil perhitungan PT Lentera Abadi Surakarta dengan hasil penelitian.
Data yang digunakan adalah data primer dan data sekunder yang meliputi data mengenai
harga pokok produksi yang dilakukan PT Lentera Abadi Surakarta, serta gambaran umum
perusahaan. Metode pengumpulan data yang dilakukan dalam penyusunan Tugas Akhir
ini adalah wawancara, observasi dan dokumentasi. Berdasarkan perhitungan dan analisis
yang telah dilakukan, terdapat selisih harga pokok produksi perusahaan dengan metode
harga pokok pesanan pada pesanan end table sebesar Rp 27.512 dan pesanan carved
table sebesar Rp 85.988. Selisih ini terjadi karena dalam menghitung harga pokok
produksi perusahaan memasukkan biaya pemasaran, biaya administrasi dan umum ke
dalam komponen biaya overhead pabrik dan tidak memasukkan biaya PBB.
Kata Kunci : Harga Pokok Produksi, Metode Harga Pokok Pesanan 


\section{PENDAHULUAN \\ Latar Belakang}

Harga pokok produksi merupakan unsur yang paling penting dalam menentukan harga jual, dimana di dalam harga jual terdapat proporsi laba yang akan diterima oleh perusahaan. Dalam menentukan harga pokok produksi diperlukan ketelitian dan penggunaan metode yang tepat. Hal ini dilakukan untuk menghindari kesalahan dalam perhitungan harga pokok produksi, yang nantinya akan merugikan perusahaan. Apabila penentuan harga pokok produksi terlalu tinggi maka harga jualnya akan menjadi tinggi, demikian sebaliknya apabila penentuan harga pokok terlalu produksi terlalu rendah maka harga jualnya juga rendah. Harga jual produk terlalu tinggi dapat membuat perusahaan sulit bersaing dengan perusahaan lain yang menawarkan harga lebih rendah, sedangkan perhitungan harga jual yang rendah akan merugikan perusahaan karena laba yang diperoleh juga rendah. PT Lentera Abadi Surakarta yang terletak di Desa Cangkringan, Banyudono, Boyolali, Jawa Tengah, merupakan perusahaan manufaktur yang memproduksi mebel. Produk yang dikerjakan adalah mebel interior ruangan seperti end table, oval table, live edge bench, live edge side table, carved table, twist plant stand,carved leg console. Perusahaan melakukan proses produksi setelah menerima pesanan dari pelanggan. PT Lentera Abadi Surakarta dalam menentukan harga pokok produksinya masih menjumlahkan seluruh taksiran biaya yang terpakai selama proses produksi dibagi dengan jumlah produksinya, perhitungan harga pokok tersebut kurang efektif karena perusahaan tidak memperhitungkan secara rinci unsur-unsur biaya produksinya. Perusahaan yang memproduksi produk berdasarkan pesanan dari pelanggan tentu harga pokok yang satu dengan yang lainya berbeda, maka perlu dilakukan perhitungan harga pokok produksi dengan metode harga pokok pesanan pada PT Lentera Abadi Surakarta.

\section{Perumusan Masalah}

a. Bagaimana perhitungan harga pokok produksi dengan metode harga pokok pesanan pada PT Lentera Abadi Surakarta tahun 2017 untuk produk end table dan carved table?

b. Berapa selisih hasil perhitungan harga pokok produksi produk end table dan carved table antara metode harga pokok pesanan dengan perhitungan yang dilakukan oleh PT Lentera Abadi Surakarta tahun 2017 ?

\section{Tujuan Penelitian}

a. Untuk menghitung harga pokok produksi menggunakan metode harga pokok pesanan produk end table dan carved table pada PT Lentera Abadi Surakarta tahun 2017.

b. Untuk mengetahui selisih perhitungan harga pokok produksi antara metode harga pokok pesanan dengan perhitungan yang dilakukan oleh PT Lentera Abadi Surakarta tahun 2017 untuk produk end table dan carved table.

\section{TINJAUAN PUSTAKA}

\section{Pengertian Harga Pokok Produksi}

Menurut Horngren (2006:45), harga pokok produksi adalah biaya barang yang dibeli untuk diproses sampai selesai, baik sebelum maupun selama periode akuntansi berjalan. Harga pokok produksi adalah total biaya barang yang diselesaikan selama periode berjalan (Hansen dan Mowen, 2004:53).

Dari pengertian harga pokok produksi diatas dapat disimpulkan bahwa harga pokok produksi adalah biaya yang dikeluarkan untuk menghasilkan/membuat barang yang telah selesai diproduksi dalam periode tertentu.

\section{Metode Harga Pokok Pesanan}

Metode harga pokok pesanan adalah metode pengumpulan harga pokok produk di mana biaya dikumpulkan untuk setiap pesanan atau kontrak atau jasa secara terpisah, dan setiap pesanan atau kontrak dapat dipisahkan identitasnya (Supriyono, 2015:36).

Menurut Mulyadi (2012:38), metode pengumpulan biaya produksi dengan 
metode harga pokok pesanan yang digunakan dalam perusahaan yang produksinya berdasarkan pesanan memiliki karakteristik sebagai berikut:

a. Perusahaan memproduksi berbagai macam produk sesuai dengan spesifikasi pemesan dan setiap jenis produk perlu dihitung harga pokok produksinya secara individual.

b. Biaya produksi harus digolongkan berdasarkan hubunganya dengan produk menjadi dua kelompok berikut ini: biaya produksi langsung dan tidak langsung.

c. Biaya produksi langsung terdiri dari biaya bahan baku dan biaya tenaga kerja langsung sedangkan biaya produksi tidak langsung disebut dengan istilah biaya overhead pabrik.

d. Biaya produksi langsung diperhitungkan sebagai harga pokok produksi pesanan tertentu berdasarkan biaya yang sesungguhnya terjadi, sedangkan biaya overhead pabrik diperhitungkan ke dalam harga pokok pesanan berdasarkan tarif yang ditentukan di muka.

e. Harga pokok per unit dihitung pada saat pesanan selesai diproduksi dengan cara membagi jumlah biaya produksi yang dikeluarkan untuk pesanan tersebut dengan jumlah unit produksi yang dihasilkan dalam pesanan yang bersangkutan.

Prosedur Akuntansi Biaya dengan Metode Harga Pokok Pesanan

Menurut Supriyono (2015:61), prosedur akuntansi biaya pada metode harga pokok pesanan meliputi organisasi formulir, catatan dan laporan yang terkoordinasi dalam rangka melaksanakan kegiatan untuk melayani pesanan dan menyajikan informasi biaya bagi manajemen. Berikut merupakan kelompok prosedur akuntansi biaya:

Prosedur Akuntansi Biaya Bahan Dan Suplies

Menurut Supriyono (2015:61), prosedur akuntansi biaya bahan dan suplies meliputi prosedur pembelian sampai dengan pemakaian bahan dan suplies di dalam pabrik.

\section{Prosedur Akuntansi Biaya Tenaga Kerja}

Menurut Supriyono (2015:66), prosedur akuntansi biaya tenaga kerja meliputi prosedur terjadinya gaji dan upah, pembayaran gaji dan upah, dan distribusi gaji dan upah untuk semua karyawan perusahaan baik produksi maupun non produksi, baik karyawan yang gajinya tetap per bulan maupun yang ditentukan oleh jam kerjanya.

\section{Prosedur Akuntansi Biaya Overhead Pabrik}

Menurut Supriyono (2015:71), biaya overhead pabrik merupakan biaya yang paling komplek, untuk keadilan dan ketelitian pembebanan harus digunakan tarip biaya overhead pabrik yang ditentukan di muka.

Penentuan Tarif Biaya Overhead Pabrik

Supriyono (2015:320) menyatakan bahwa penentuan tarif biaya overhead pabrik meliputi langkah-langkah sebagai berikut:

a. Penentuan Budget (anggaran) Biaya Overhead Pabrik

Pada awal periode disusun budget untuk setiap elemen biaya overhead pabrik yang digolongkan ke dalam biaya tetap dan variabel.

b. Penetuan dasar pembebanan dan tingkat kapasitas

Setelah budget biaya overhead pabrik ditentukan, langkah selanjutnya adalah memilih dasar pembebanan biaya dan tingkatan kapasitas. Pada umumnya dasar yang dipakai untuk menetukan tingkatan kapasitas adalah kapasitas normal sedangkan beberapa dasar pembebanan yang dipakai adalah jam kerja langsung.

Menurut Supriyono (2015:310), dasar jam kerja langsung bermanfaat untuk menghilangkan kelemahan yang disebabkan tarif upah yang berfluktuasi dari waktu ke waktu dan perbedaan tarif upah karena tingkat keahlian karyawan. Rumus perhitungan tarif atas dasar jam kerja langsung adalah:

$$
\text { Tarif } B O P=\frac{\text { Budget Biaya Overhead Pabrik }}{\text { Budget Jam Kerja Langsung }}
$$


c. Perhitungan Tarif Biaya Overhead Pabrik

Tarif biaya overhead pabrik dihitung dari budget biaya overhead pabrik dibagi dengan dasar pembebanan biaya dan tingkat kapasitas yang dipakai. adalah menghitung tarif biaya overhead pabrik. Untuk pengendalian biaya overhead pabrik tarif dihitung baik tarif total, maupun tarif tetap dan tarif variabel.

Menurut Supriyono (2015:71), rumus perhitungan tarif biaya overhead pabrik adalah sebagai berikut:

$$
T=\frac{\mathrm{B}}{\mathrm{K}}
$$

Keterangan:

$\mathrm{T}=$ Tarif biaya overhead pabrik

$\mathrm{B}=$ Budget biaya overhead pabrik periode tertentu

$\mathrm{K}=$ Budget kapasitas pembebanan untuk periode yang bersangkutan

Menurut Supriyono (2015:72), Apabila tarif biaya overhead pabrik sudah ditentukan, prosedur akuntansi biaya overhead pabrik selanjutnya sebagai berikut:

a. Prosedur Pembebanan Biaya

Overhead Pabrik pada Pesanan

Suatu pesanan akan dibebani biaya overhead pabrik sesuai dengan kapasitas sesungguhnya dinikmati pesanan dikalikan dengan tarif biaya overhead pabrik yang ditentukan dimuka.

\section{METODE PENELITIAN}

\section{Pengertian Metode Penelitian}

Menurut Sugiyono (2007:2) Metode penelitian merupakan cara ilmiah untuk mendapatkan data dengan tujuan dan kegunaan tertentu.

Metode penelitian yang digunakan dalam penyusunan Tugas Akhir ini meliputi jenis data, metode pengumpulan data, dan metode penulisan serta metode analisis data.

\section{Klasifikasi Data}

\section{Jenis Data Menurut Sifatnya}

Berdasarkan sifatnya, data yang digunakan dalam Tugas Akhir ini adalah: a. Data Kuantitatif
Data kuantitatif adalah angka-angka hasil observasi atau pengukuran (Soeratno dan Arsyad, 2008:67). Data yang digunakan dalam penulisan Tugas Akhir ini adalah data yang berhubungan dengan harga pokok produksi yaitu biaya bahan baku, biaya tenaga kerja, dan biaya overhead pabrik pada PT Lentera Abadi Surakarta.

b. Data Kualitatif

Data kualitatif adalah data yang dicatat bukan dengan angka-angka tetapi dengan menggunakan klasifikasi-klasifikasi (Soeratno dan Arsyad, 2008:68). Data yang digunakan dalam penulisan Tugas Akhir ini adalah gambaran umum perusahaan yang meliputi sejarah berdirinya, struktur organisasi dan proses produksi pada PT Lentera Abadi Surakarta.

\section{Jenis Data Menurut Sumbernya}

Berdasarkan sumbernya, data yang digunakan dalam Tugas Akhir ini adalah:

a. Data Primer

Menurut Soeratno dan Arsyad (2008:70), data primer adalah data yang dikumpulkan dan diolah oleh organisasi yang menerbitkan atau menggunakanya. Data ini diperoleh secara langsung dengan mengadakan wawancara kepada pegawai di bagian keuangan serta bagian yang terkait dengan perhitungan biaya produksi dan laporan penjualan pada PT Lentera Abadi Surakarta.

b. Data Sekunder

Menurut Soeratno dan Arsyad (2008:71), data sekunder adalah data yang diterbitkan atau digunakan oleh organisasi yang bukan pengolahnya. Data sekunder yang digunakan adalah gambaran umum PT Lentera Abadi Surakarta.

\section{Metode Pengumpulan Data}

Dalam penulisan Tugas Akhir ini terdapat dua metode pengumpulan data yang akan digunakan adalah sebagai berikut:

a. Wawancara

Menurut Soeratno dan Arsyad (2008:86), wawancara merupakan metode pengumpulan data dengan cara bertanya langsung 
(berkomunikasi langsung) dengan responden. Wawancara ini dilakukan dengan cara tanya-jawab secara langsung pada bagian keuangan dan bagian produksi mengenai biaya produksi pada PT Lentera Abadi Surakarta.

b. Observasi

Menurut Soeratno dan Arsyad (2008:83), observasi adalah cara pengumpulan data dengan cara melakukan pencatatan secara cermat dan sistematik. Observasi dilakukan pada bagian produksi dengan cara melihat dan mengamati proses pembuatan produk pada PT Lentera Abadi Surakarta.

c. Dokumetasi

\begin{tabular}{lrr} 
Menurut & \multicolumn{2}{c}{ Sugiyono } \\
dokumen & merupakan & catatan \\
peristiwa yang sudah & berlalu. \\
Dokumen dalam penelitian & Tugas \\
Akhir ini adalah data berupa & sejarah \\
dan rekapitulasi penjualan & tahun \\
2016 pada PT Lentera & Abadi \\
Surakarta. & &
\end{tabular}

\section{Metode Penulisan}

Dalam penulisan Tugas Akhir ini, metode penulisan yang digunakan adalah sebagai berikut:

a. Metode Deskripsi

Menurut Alek dan Achmad (2011:184), penulisan yang menggambarkan bentuk objek pengamatan, rupanya, sifatnya, rasanya dan coraknya termasuk pemerian. Metode deskripsi yang disajikan dalam Tugas Akhir ini adalah gambaran umum PT Lentera Abadi Surakarta yang meliputi sejarah berdirinya, struktur organisasi dan proses produksi.

b. Metode Eksposisi

Menurut Alek dan Achmad (2011:183), penulisan yang bertujuan memberikan informasi, penjelasan, keterangan, atau pemahaman termasuk golongan pemaparan. Metode ini digunakan untuk menentukan harga pokok produksi secara akurat dengan menggunakan metode harga pokok pesanan.

Metode Analisis Data

Metode analisis data yang digunakan adalah metode analisis komparasi.
Analisis ini digunakan dengan membandingkan hasil perhitungan harga pokok produksi yang dilakukan perusahaan dengan perhitungan harga pokok produksi dengan metode harga pokok pesanan.

a. Perhitungan harga pokok produksi PT Lentera Abadi Surakarta

1. Menjumlahkan seluruh biaya yang dikeluarkan untuk memproduksi pesanan dari pelanggan.

2. Seluruh biaya yang dikeluakan untuk memproduksi pesanan tersebut dibagi dengan jumlah pesanan.

b. Perhitungan harga pokok produksi dengan metode harga pokok pesanan

1. Menggolongkan biaya berdasarkan unsur biaya produksi yang meliputi biaya bahan baku, biaya tenaga kerja langsung dan biaya overhead pabrik.

2. Menghitung tarif biaya overhead pabrik yang dibebankan pada pesanan berdasarkan jam kerja langsung.

3. Dari data tersebut dapat dilakukan perhitungan harga pokok produk per unit dengan membagi biaya produksi yang dikeluarkan untuk memproduksi pesanan tersebut dengan jumlah unit produksi yang dihasilkan dalam pesanan yang bersangkutan.

c. Melakukan analisis komparasi antara hasil perhitungan harga pokok produksi yang dilakukan PT Lentera Abadi Surakarta dengan hasil perhitungan harga pokok produksi dengan metode harga pokok pesanan.

\section{HASIL DAN PEMBAHASAN \\ Gambaran Umum Perusahaan}

PT Lentera Abadi Surakarta merupakan perusahaan pengolahan kayu dengan produksi mebel indoor furniture berdasarkan pesanan dari konsumen yang terletak di desa Cangkringan, Banyudono, Boyolali. Perusahaan ini didirikan pada tahun 1995 oleh Bapak Joko Suharyono yang pada mulanya bernama CV Suka Lentera Abadi, kemudian pada tanggal 23 oktober 2014 berubah nama menjadi PT Lentera Abadi Surakarta dan disahkan dengan akta 
notaris atas dasar SIUP No. 510.4/192/30/PM/II/2015.

\section{Pembahasan}

\section{Unsur-unsur Biaya Produksi}

Unsur-unsur harga pokok meliputi semua biaya yang dikeluarkan untuk memproses bahan baku menjadi barang jadi dalam periode tertentu atau disebut juga dengan biaya produksi. Biaya produksi ini terdiri dari biaya bahan baku, biaya tenaga kerja langsung, dan biaya overhead pabrik.

\section{Biaya Bahan}

Bahan baku adalah bahan yang akan diolah menjadi produk selesai. Bahan baku untuk pembuatan end table, dan carved table yaitu menggunakan kayu mahoni dan MDF (Medium Density Board).

Perhitungan Biaya Bahan Baku Pesanan

\begin{tabular}{|c|c|c|c|c|c|c|}
\hline $\begin{array}{c}\text { Jenis } \\
\text { Pesanan }\end{array}$ & $\begin{array}{c}\text { Bahan } \\
\text { Baku }\end{array}$ & $\begin{array}{c}\text { Ukuran } \\
\text { Kayu }\end{array}$ & Kebutuhan & $\begin{array}{c}\text { Harga } \\
(\mathrm{Rp})\end{array}$ & Unit & Jumlah ( $R p)$ \\
\hline \multirow{3}{*}{$\begin{array}{l}\text { End } \\
\text { table }\end{array}$} & $\begin{array}{l}\text { Kayu } \\
\text { Mahoni }\end{array}$ & $\begin{array}{l}0,0076 \\
\mathrm{~m} 3 / \mathrm{pcs}\end{array}$ & $4,56 \mathrm{~m} 3$ & 4.350 .000 & 600 & 19.836 .000 \\
\hline & $\begin{array}{ll}\mathrm{MDF} & 6 \\
\mathrm{~mm} & \\
\end{array}$ & $\begin{array}{l}0,07 \\
\text { lembar/pcs }\end{array}$ & 42 lembar & 75.000 & 600 & 3.150 .000 \\
\hline & $\begin{array}{ll}\mathrm{MDF} & 9 \\
\mathrm{~mm} & \\
\end{array}$ & $\begin{array}{l}0,07 \\
\text { lembar/pcs }\end{array}$ & 42 lembar & 110.500 & 600 & 4.641 .000 \\
\hline \multicolumn{6}{|l|}{ Jumlah } & 27.627 .000 \\
\hline \multirow{2}{*}{$\begin{array}{c}\text { Carved } \\
\text { table }\end{array}$} & $\begin{array}{l}\text { Kayu } \\
\text { Mahoni }\end{array}$ & $\begin{array}{l}0,0319 \\
\mathrm{~m} 3 / \mathrm{pcs}\end{array}$ & $15,95 \mathrm{~m} 3$ & 4.350 .000 & 500 & 69.382 .500 \\
\hline & $\begin{array}{ll}\mathrm{MDF} & 6 \\
\mathrm{~mm} & \\
\end{array}$ & $\begin{array}{l}0,154 \\
\text { lembar/pcs }\end{array}$ & 72 lembar & 75.000 & 500 & 5.775 .000 \\
\hline \multicolumn{6}{|c|}{ Jumlah } & 74.157 .500 \\
\hline \multicolumn{6}{|c|}{ Jumlah Pemakaian Biaya Bahan Baku } & 101.784 .500 \\
\hline
\end{tabular}

Sumber: Data yang diolah, Tahun 2017

\section{Biaya Tenaga Kerja Langsung}

Waktu yang dibutuhkan untuk menyelesaikan pesanan end table adalah 28 hari, dan pesanan carved table adalah 34 hari. Perhitungan biaya tenaga kerja langsung yang dibutuhkan untuk memenuhi pesanan end table daan carved table dapat dilihat pada tabel berikut:

Perhitungan Biaya Tenaga Kerja Langsung 600 unit End Table

\begin{tabular}{|l|c|c|r|r|r|}
\hline \multicolumn{1}{|c|}{$\begin{array}{c}\text { Aktivitas } \\
\mathbf{( 1 )}\end{array}$} & $\begin{array}{c}\text { Jumlah } \\
\text { Karyawan } \\
\mathbf{( 2 )}\end{array}$ & $\begin{array}{c}\text { Jam } \\
\text { Kerja } \\
\mathbf{( 3 )}\end{array}$ & $\begin{array}{c}\text { Total Jam } \\
\text { Kerja } \\
\mathbf{( 4 )}(\mathbf{2}) \mathbf{x}(\mathbf{3})\end{array}$ & $\begin{array}{c}\text { Tarif Per } \\
\text { Jam (Rp) } \\
\mathbf{( 5 )}\end{array}$ & $\begin{array}{c}\text { Jumlah Biaya } \\
\text { (6) = (4) } \mathbf{~ ( 5 ) ~} \\
\text { (Rp) }\end{array}$ \\
\hline Pemotongan & 11 & 224 & 2.464 & 9.000 & 22.176 .000 \\
\hline Perakitan & 20 & 224 & 4.480 & 10.000 & 44.800 .000 \\
\hline Finishing & 18 & 224 & 4.032 & 11.000 & 44.352 .000 \\
\hline Jumlah & $\mathbf{4 9}$ & & $\mathbf{1 0 . 9 7 6}$ & & $\mathbf{1 1 1 . 3 2 8 . 0 0 0}$ \\
\hline
\end{tabular}

Sumber: Data yang diolah, Tahun 2017

Jumlah Jam Kerja $=28$ hari $x 8$ jam/hari $=224 \mathrm{JKL}$

Perhitungan Biaya Tenaga Kerja Langsung 500 unit Carved Table

\begin{tabular}{|l|c|c|r|r|r|}
\hline \multicolumn{1}{|c|}{$\begin{array}{c}\text { Aktivitas } \\
(\mathbf{1})\end{array}$} & $\begin{array}{c}\text { Jumlah } \\
\text { Karyawan } \\
(\mathbf{2})\end{array}$ & $\begin{array}{c}\text { Jam } \\
\text { Kerja } \\
(\mathbf{3})\end{array}$ & $\begin{array}{c}\text { Total Jam } \\
\text { Kerja } \\
(\mathbf{4})=(\mathbf{2}) \mathbf{x}(3)\end{array}$ & $\begin{array}{c}\text { Tarif Per } \\
\text { Jam (Rp) } \\
(\mathbf{5})\end{array}$ & $\begin{array}{c}\text { Jumlah Biaya } \\
(\mathbf{6})=(\mathbf{4}) \mathbf{x}(\mathbf{5}) \\
(\mathbf{R p})\end{array}$ \\
\hline Pemotongan & 11 & 272 & 2.992 & 9.000 & 26.928 .000 \\
\hline Perakitan & 20 & 272 & 5.440 & 10.000 & 54.400 .000 \\
\hline Finishing & 18 & 272 & 4.896 & 11.000 & 53.856 .000 \\
\hline Jumlah & $\mathbf{4 9}$ & & $\mathbf{1 3 . 3 2 8}$ & & 135.184 .000 \\
\hline
\end{tabular}

Sumber: Data yang diolah, Tahun 2017

Jumlah Jam Kerja $=34$ hari x 8 jam/hari $=272$ JKL 
Biaya Overhead Pabrik Sesungguhnya Tahun 2016

\begin{tabular}{|c|c|c|c|}
\hline No & Elemen Biaya Overhead Pabrik & Biaya Tetap & Biaya Variabel \\
\hline 1 & Biaya bahan penolong & & Rp 126.903 .000 \\
\hline 2 & Biaya tenaga kerja tidak langsung & $\operatorname{Rp} 45.240 .000$ & - \\
\hline 3 & Biaya reparasi dan pemeliharaan & Rp $\quad 3.314 .500$ & - \\
\hline 4 & Biaya penyusutan gedung pabrik & $\operatorname{Rp} 12.500 .000$ & - \\
\hline 5 & Biaya penyusutan mesin pabrik & $\operatorname{Rp} 10.000 .000$ & - \\
\hline 6 & Biaya penyusutan kendaraan pabrik & Rp 14.375 .000 & - \\
\hline 7 & Biaya penyusutan peralatan pabrik & $\operatorname{Rp} \quad 2.450 .000$ & - \\
\hline 8 & Biaya air pabrik & $\mathrm{Rp} \quad 1.552 .000$ & - \\
\hline 9 & Biaya listrik pabrik & 804.384 & Rp 15.481 .265 \\
\hline 10 & Biaya packing & - & Rp 98.840 .000 \\
\hline 11 & Biaya overhead pabrik lain-lain: & & \\
\hline & Biaya telepon & - & 525.000 \\
\hline & Biaya bahan bakar & - & 2.373 .800 \\
\hline & Biaya PBB & $\mathrm{Rp} \quad 1.935 .000$ & - \\
\hline \multicolumn{2}{|c|}{ Jumlah Biaya } & Rp 90.619.384 & Rp 245.675.065 \\
\hline \multicolumn{2}{|c|}{ Estimasi Jkl } & \multicolumn{2}{|c|}{$111.230 \mathrm{Jkl}$} \\
\hline \multicolumn{2}{|c|}{ Tarif BOP/Jkl } & $\operatorname{Rp} 815$ & Rp 2.208 \\
\hline Tar & total BOP/Jkl & \multicolumn{2}{|c|}{$\operatorname{Rp} 3.023$} \\
\hline
\end{tabular}

Sumber: Data yang diolah, Tahun 2017

Pembebanan Biaya Overhead Pabrik pada Produk

\begin{tabular}{|l|c|c|r|}
\hline \multicolumn{1}{|c|}{ Jenis Pesanan } & $\begin{array}{c}\text { Kapasitas } \\
\text { Sesungguhnya JKL }\end{array}$ & $\begin{array}{c}\text { Tarif } \\
(\mathbf{R p})\end{array}$ & $\begin{array}{c}\text { Biaya Overhead Pabrik } \\
\text { yang Dibebankan (Rp) }\end{array}$ \\
\hline End Table & 10.976 & 3.023 & 33.180 .448 \\
\hline Carved Table & 13.328 & 3.023 & 40.290 .544 \\
\hline Jumlah & & 73.470 .992 \\
\hline
\end{tabular}

Sumber: Data yang diolah, Tahun 2017

Perhitungan Harga Pokok Produksi Per Unit

\begin{tabular}{|l|r|r|}
\hline \multicolumn{2}{|c|}{ Elemen Biaya Produksi } & \multicolumn{2}{|c|}{ Jenis Pesanan } \\
\cline { 2 - 3 } & End Table (Rp) & Carved Table (Rp) \\
\hline Biaya Bahan Baku & 27.627 .000 & 74.157 .500 \\
\hline Biaya Tenaga Kerja Langsung \\
$\begin{array}{l}\text { Biaya Overhead Pabrik yang } \\
\text { dibebankan }\end{array}$ & 111.328 .000 & 135.184 .000 \\
\hline Jumlah Biaya Produksi & 33.180 .448 & 40.290 .554 \\
\hline Kuantitas Produksi & $\mathbf{1 7 2 . 1 3 5 . 4 4 8}$ & $\mathbf{2 4 9 . 6 3 2 . 0 5 4}$ \\
\hline Harga Pokok Produksi per unit & 600 unit & 500 unit \\
\hline
\end{tabular}

Sumber: Data yang diolah, Tahun 2017

Perhitungan Harga Pokok Produksi menurut PT Lentera Abadi Surakarta

\begin{tabular}{|l|c|r|}
\multirow{2}{*}{\multicolumn{1}{c}{ Elemen Biaya Produksi }} & \multicolumn{2}{|c|}{ Jenis Pesanan } \\
\cline { 2 - 3 } & $\begin{array}{c}\text { End Table } \\
(\mathrm{Rp})\end{array}$ & \multicolumn{1}{c|}{ Carved Table (Rp) } \\
\hline Biaya Bahan Baku & 27.627 .000 & 74.157 .500 \\
\hline Biaya Tenaga Kerja Langsung & 111.328 .000 & 135.184 .000 \\
\hline Biaya Overhead Pabrik & 49.687 .400 & $\mathbf{2 9 2 . 2 8 4 . 6 0 0}$ \\
\hline Jumlah Biaya Produksi & $\mathbf{1 8 8 . 6 4 2 . 4 0 0}$ & \multicolumn{1}{c|}{500 unit } \\
\hline Kuantitas Produksi & 600 unit & $\mathbf{5 8 5 . 2 5 2}$ \\
\hline Harga Pokok Produksi per unit & $\mathbf{3 1 4 . 4 0 4}$ & \\
\hline
\end{tabular}

Sumber: Data yang diolah, Tahun 2017 
Tabel Perbandingan Hasil Perhitungan Harga Pokok Produksi

\begin{tabular}{|l|r|r|}
\hline \multicolumn{1}{|c|}{ Perhitungan } & End Table $(\boldsymbol{R} p)$ & \multicolumn{1}{c|}{ Carved Table $(\boldsymbol{R} \boldsymbol{p})$} \\
\hline PT Lentera Abadi Surakarta & 314.404 & 585.252 \\
\hline Metode Harga Pokok Pesanan & 286.892 & 499.264 \\
\hline Selisih & $\mathbf{2 7 . 5 1 2}$ & $\mathbf{8 5 . 9 8 8}$ \\
\hline
\end{tabular}

Sumber: Data yang diolah, Tahun 2017

Perusahaan dengan perhitungan harga pokok produksi menurut metode harga pokok pesanan yaitu sebesar Rp 113.500. Selisih tersebut timbul karena adanya perbedaan perhitungan harga pokok produksi per unit yaitu produk end table sebesar Rp 27.512 dan produk carved table sebesar $\mathrm{Rp}$ 85.988. Hasil perhitungan harga pokok produksi dengan metode harga pokok pesanan untuk pesanan end table dan carved table lebih rendah dari perhitungan perusahaan. Perbedaan hasil perhitungan tersebut terjadi karena perbedaan elemen biaya overhead pabrik, dalam biaya overhead pabrik perusahaan terdapat biaya pemasaran, biaya administrasi dan umum karena biaya tersebut bukan termasuk dalam elemen biaya overhead pabrik. Sehingga mengakibatkan perusahaan terlalu tinggi dalam menetapkan harga pokok produk tersebut.

\section{KESIMPULAN \\ Kesimpulan}

Berdasarkan hasil perhitungan harga pokok produksi dengan metode harga pokok pesanan pada PT Lentera Abadi Surakarta untuk produk end table dan produk carved table dapat disimpulkan bahwa:

a. Besarnya harga pokok produksi untuk setiap unit produk dengan metode harga pokok pesanan untuk produk pesanan end table sebesar Rp 286.892 dan produk pesanan carved table sebesar Rp 499.264.

b. Terdapat selisih besarnya harga pokok produksi produk menurut PT Lentera Abadi Surakarta dengan perhitungan harga pokok produksi menggunakan metode harga pokok pesanan untuk produk pesanan end table sebesar Rp 27.512 dan produk pesanan carved table sebesar Rp 85.988. Selisih tersebut terjadi karena perusahaan memasukkan biaya pemasaran, biaya administrasi dan umum ke dalam biaya overhead pabrik dan di dalam biaya overhead pabrik perusahaan belum ada biaya PBB, sehingga perusahaan terlalu tinggi dalam menetapkan harga pokok produksi.

\section{DAFTAR PUSTAKA}

Alek dan Achmad. 2011. Bahasa Indonesia Untuk Perguruan Tinggi. Jakarta: Kencana

Bustami, Bastian dan Nurlela. 2013. Akuntansi Biaya: Teori dan Aplikasi. Yogyakarta: Graha Ilmu

Daljono. 2011. Akuntansi Biaya Penentuan Harga Pokok \& Pengendalian.

Semarang: BP UNDIP

Hansen dan Mowen. 2004. Akuntansi Manajemen. Penerjemah Dewi Fitriasari dan Deny Arnos Kwary. Jakarta: Salemba Empat

Horngren, Charles., Srikant M. Datar dan George Foster. 2006. Akuntansi Biaya: Penekanan Manajerial. Terjemahan Lestari. Jakarta: Erlangga

Mulyadi. 2012. Akuntansi Biaya. Yogyakarta: UPP AMP YKPN

Soeratno dan Lincolin Arsyad. 2008. Metodologi Penelitian Untuk Ekonomi Dan Bisnis. Yogyakarta: UPP STIM YKPN

Sugiyono. 2007. Metode Penelitian Kuantitatif, Kualitatif dan $R \& D$. Bandung: IKAPI

Supriyono. R.A. 2015. Akuntansi Biaya: Pengumpulan Biaya dan Penentuan Harga Pokok. Yogyakarta: BPFE-Yogyakarta. 